

Published by DiscoverSys

\section{Laporan Kasus: Perimortem Sectio Caesarean pada Ibu Hamil dengan Henti Jantung}

\author{
Yanti Permatasari, ${ }^{1 *}$ Willy Yant Kartolo ${ }^{2}$
}

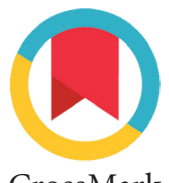

CrossMark

\title{
ABSTRACT
}

Background: Perimortem caesarean section (PMCS) was done in pregnant women with no hope for survival, and not responding to initial resuscitative maneuver. The primary aim of PMCS procedure is to empty the uterus to aid maternal resuscitation.

Case Presentation: We performed a PMCS after no response of cardiopulmonary resuscitation (CPR) in a 19 years old woman with severe preeclampsia, severe anemia, and acute lung edema.
Conclusion: This is a case report of PMSC procedure performed in maternal cardiac arrest. The PMCS was done after no response of CPR with left uterine displacement (LUD). However, the outcome of maternal and neonatal deaths was unavoidable.

Keywords: Perimortem cesarean section, maternal cardiao pulmonary arrest, pregnant woman, resuscitation Cite This Article: Permatasari, Y., Kartolo, W.Y. 2018. Laporan Kasus: Perimortem Sectio Caesarean pada Ibu Hamil dengan Henti Jantung. . Intisari Sains Medis 9(2): 141-145. DOl: 10.1556/ism.v9i2.196

ABSTRAK

Latar Belakang: Perimortem Sectio Caesarea (PMSC) dilakukan pada ibu hamil yang tidak memiliki harapan untuk bertahan hidup dan tidak merespon terhadap resusistasi awal. Tujuan utama dari PMSC adalah untuk mengosongkan uterus sehingga memperbaiki resusitasi maternal.

Kasus: Kami melakukan PMSC setelah tidak ada respon terhadap resusitasi jantung paru (RJP) pada wanita berusia 19 tahun, G1P0A0 dengan usia kehamilan 29 minggu, sesak napas dengan penyebab anemia berat dan edema paru akut, dan preeklampsia berat.

Kesimpulan: Tindakan PMSC ini dilakukan pada ibu hamil yang mengalami henti jantung. PMSC dilakukan setelah tidak adanya respon dari RJP dengan penggeseran uterus ke kiri (left uterine displacement / LUD). Namun, kematian dari ibu dan bayi tidak dapat dihindari.

Kata kunci: Perimortem Sectio Caesarea, henti jantung, ibu hamil, resusitasi

Cite Pasal Ini: Permatasari, Y., Kartolo, W.Y. 2018. Laporan Kasus: Perimortem Sectio Caesarean pada Ibu Hamil dengan Henti Jantung. . Intisari Sains Medis 9(2): 141-145. D0I: 10.1556/ism.v9i2.196

'Dokter Spesialis Anestesi,

${ }^{2}$ Dokter Umum, Kelompok Staf Medis Anestesiologi dan Terapi Intensif

Rumah Sakit Umum Daerah Mgr. Gabriel Manek, SVD,Atambua, Indonesia
*Korespondensi: Yanti Permatasari, Dokter Spesialis Anestesi Rumah Sakit Umum Daerah Mgr. Gabriel Manek, SVD, Atambua, Indonesia ataanest@gmail.com

\section{PENDAHULUAN}

Dibandingkan wanita dewasa yang tidak hamil, ibu hamil memiliki kurang dari 4-6 menit untuk terjadinya kerusakan otak selama henti jantung berlangsung akibat perubahan fisiologis pada ibu hamil. Selama kehamilan berlangsung, terjadi peningkatan stroke volume, detak jantung, dan cardiac output secara progresif hingga puncaknya terjadi di trisemester ketiga dimana cardiac output dapat meningkat $45 \%$ dari sebelum kehamilan. ${ }^{1}$

Parameter yang penting bagi kelangsungan hidup janin, antara lain adalah waktu interval antara henti jantung dan lahirnya neonatus, status kesehatan ibu hamil, dan usaha resusitasi jantung paru (RJP) yang dilakukan. ${ }^{2}$ Katz dan koleganya merekomendasikan untuk melakukan perimortem sectio caesarea (PMSC) jika tidak ada respon dari bantuan hidup dasar dan lanjut selama 4 menit dan bayi dilahirkan 5 menit sejak henti jantung terjadi. PMSC dilakukan untuk menjamin hasil yang terbaik bagi bayi dan memfasilitasi RJP yang lebih baik pada ibu. ${ }^{3,4,5}$

Rekomendasi terkini menyatakan bahwa PMSC harus dilakukan pada wanita hamil yang tidak memiliki harapan untuk bertahan hidup, dan bagi wanita hamil yang tidak berespon terhadap tindakan resusitasi. ${ }^{4,5}$ Jadi, tujuan utama dari prosedur PMSC adalah untuk mengosongkan uterus agar memperbaiki resusitasi ibu, bukan kelangsungan hidup janin, dan monitoring janin tidak dilakukan selama RJP. ${ }^{6}$

Terdapat pertimbangan-pertimbangan khusus pada resusitasi jantung paru pada ibu hamil, 
terlebih lagi pada kehamilan semester kedua dan lebih. Pada kehamilan lanjut (usia kehamilan lebih dari 21 - 24 minggu), efektivitas dari RJP berkurang karena kompresi aortocaval menghambat venous return ke jantung. ${ }^{4,5,7,8}$ Lahirnya bayi akan segera meringankan kompresi aortocaval dan akan meningkatkan venous return dan cardiac output. Pada wanita tidak hamil yang dilakukan resusitasi jantung paru, kompresi dada hanya memberikan $30 \%$ dari normal cardiac output. Pada wanita hamil dengan kompresi aortacaval, akan turun hingga $10 \%$ selama RJP.,5 Jadi, pada pasien hamil lanjut, uterus harus dipindahkan secara manual ke sisi kiri pasien (left uterine displacement atau LUD) selama RJP., ${ }^{4,5}$ Kelangsungan hidup janin berhubungan erat dengan usia kehamilan. Semakin besar usia kehamilan, semakin besar kesempatan bayi untuk dapat bertahan.

\section{KASUS}

Wanita usia 19 tahun dengan Gestasi 1 Para 0 Abortus 0 usia kehamilan 29 minggu datang ke Instalasi Gawat Darurat rumah sakit kami pada tanggal 4 Oktober 2017 dengan keluhan utama sesak napas 2 hari sebelum masuk rumah sakit dan dirasakan bertambah berat dengan aktivitas. Pasien juga mengeluh kepala pusing dan cepat lelah.

Pada pemeriksaan didapatkan napas spontan, airway paten, laju napas $30 \mathrm{kali} / \mathrm{menit}, \mathrm{SpO}_{2} 95 \%$ dalam udara terbuka. Pada auskultasi didapatkan bunyi vesikuler pada kedua lapang paru, tidak ada bunyi napas tambahan seperti wheezing atau rhonki. Pada inspeksi, tidak ada retraksi dinding dada. Tekanan darah 140/100 mmHg, detak jantung 112 kali per menit. Tidak ada defisit neurologis. Pasien diuresis spontan. Tinggi fundus uteri $34 \mathrm{~cm}$, Detak Jantung Janin (+) $140 \mathrm{x} /$ menit, bising usus normal, tidak ada tanda-tanda inpartu. Pada pasien ditemukan edema pitting +1 pada kedua tungkai bawah. Hasil pemeriksaan laboratorium terdapat pada Tabel 1.

Pasien didiagnosis dengan G1P0A0 usia kehamilan 29 minggu dengan preeklampsia berat dan observasi dyspneu dengan diagnosa banding anemia berat dan edema paru akut. Pasien diberikan suplemen $\mathrm{O}_{2} 4$ liter per menit dengan nasal kanul, IVFD RL 1500 cc / 24 jam, nifedipin tab $10 \mathrm{mg} / 12$ jam peroral, transfusi darah PRC 1 kantong/hari, pemberian $\mathrm{MgSO}_{4}$ dengan loading dose $\mathrm{MgSO}_{4} 40 \% 4$ gram intravena setelah itu maintenance dose $\mathrm{MgSO}_{4} 40 \% 6$ gram dalam RL $500 \mathrm{cc}$ for $6 \mathrm{jam}( \pm 1 \mathrm{gram} / \mathrm{jam})$ dan pasien dipindahkan ke ruang perawatan biasa.
Tabel 1 Hasil Laboratorium

\begin{tabular}{|c|c|}
\hline Parameter & Hasil \\
\hline \multicolumn{2}{|l|}{ Darah Rutin } \\
\hline WBC & $15,9 \times 10^{3} / \mathrm{uL}$ \\
\hline $\mathrm{RBC}$ & $2,7 \times 10^{6} / \mathrm{uL}$ \\
\hline Platelet count & $819 \times 10^{3} / \mathrm{uL}$ \\
\hline Hemoglobin & $5,0 \mathrm{~g} / \mathrm{dL}$ \\
\hline Hematokrit & $18,8 \%$ \\
\hline $\mathrm{MCV}$ & $70,4 \mathrm{fL}$ \\
\hline $\mathrm{MCH}$ & $18,7 \mathrm{pq}$ \\
\hline $\mathrm{MCHC}$ & $26,6 \mathrm{~g} / \mathrm{dL}$ \\
\hline NEUT\% & $57,8 \%$ \\
\hline LYMPH\% & $33,1 \%$ \\
\hline Gula Darah Sewaktu & $70 \mathrm{mg} / \mathrm{dL}$ \\
\hline Ureum & $20 \mathrm{mg} / \mathrm{dL}$ \\
\hline Kreatinin & $0,8 \mathrm{mg} / \mathrm{dL}$ \\
\hline SGOT & $18 \mathrm{U} / \mathrm{I}$ \\
\hline SGPT & $29 \mathrm{U} / \mathrm{I}$ \\
\hline Golongan darah & 0 \\
\hline Clotting Time & 9’00" \\
\hline \multicolumn{2}{|l|}{ Urine Lengkap } \\
\hline Urobilinogen & $1+$ \\
\hline Bilirubin & $1+$ \\
\hline Keton & Negatif \\
\hline Blood & Negatif \\
\hline Protein & $3+$ \\
\hline Nitrit & Positif \\
\hline Leukosit & $1+$ \\
\hline Gluckosa & Negatif \\
\hline Specific Gravity & 1.010 \\
\hline $\mathrm{pH}$ & 5.5 \\
\hline \multicolumn{2}{|l|}{ Sedimen Urin } \\
\hline Eritrosit & Negatif \\
\hline Leukosit & $5-15$ \\
\hline Sel epitel & $0-5$ \\
\hline Sel silinder & Negatif \\
\hline Kristal & Kalsium oksalat (+) \\
\hline Bakteri & Basillus (+) \\
\hline
\end{tabular}

Selama perawatan, pada tanggal 9 Oktober 2017 di bangsal perawatan biasa, pasien mengeluh sesak napas, dengan laju napas 50 kali per menit, dangkal dan pasien gelisah. Tanda-tanda vital: tekanan darah 166/79 mmHg, denyut jantung 145 kali per menit, $\mathrm{SpO}_{2} 98 \%$ dengan suplemen $\mathrm{O}_{2} 8$ liter per menit. dokter spesialis anestesi yang bertugas 


\section{A}



B

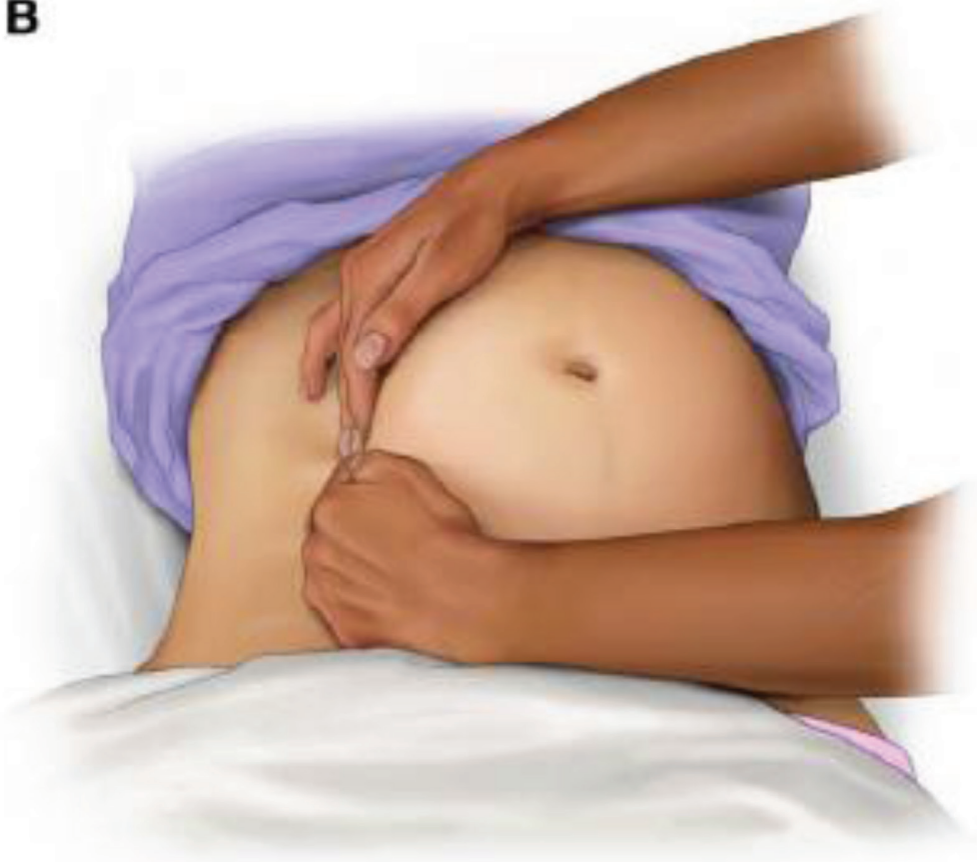

Gambar 1 A. Manual LUD, dilakukan dengan teknik satu tangan. B. Teknik dua tangan selama resusitasi ${ }^{9}$

menginstruksikan untuk mengaktifkan Code Blue, siapkan set intubasi, hubungi dokter spesialis kandungan dan dokter spesialis anak untuk datang ke RS dan menghubungi Ruangan Operasi untuk mempersiapkan operasi cito.

10 menit kemudian, pasien henti napas. Pasien mendapatkan RJP dengan LUD, tanpa pemberian defibrilasi. Detak jantung janin didapatkan 160 kali per menit. RJP tetap dilanjutkan dan tim memutuskan untuk dilakukan PMSC dan pasien dipindahkan ke ruang operasi.

PMSC dilakukan dan bayi dilahirkan 8 menit kemudian. Selama operasi didapatkan pembekuan darah pada retroperitoneal kurang lebih $1000 \mathrm{~mL}$, tanpa bekuan darah intrauterin, dan plasenta dilahirkan lengkap. Perkiraan darah yang hilang $1500 \mathrm{~mL}$. Neonatus laki-laki lahir dengan flaccid, tanpa usaha napas spontan, tetapi didapatkan detak jantung. Skor Apgar 1 saat lahir dan selanjutnya dilakukan resusitasi neonatus oleh tim dokter anak.

RJP dilakukan secara simultan pada secara terus menerus hingga pasien dinyatakan meninggal 40 menit setelah dilakukan RJP. Diagnosis klinisnya adalah preeklampsia berat dengan komplikasinya.

Skor Apgar neonatus 1/1/3 sejak menit ke-1, ke-5, dan ke-10 selama resusitasi. Setelah dilahirkan bayi tampak sianosis, bradikardi, dan tidak ada napas spontan. Setelah resusitasi dilakukan, bayi dipindahkan ke NICU. Pemeriksaan fisik didapatkan takipnea, grunting, retraksi dinding dada, dan sianosis akibat peningkatan kebutuhan oksigen. Setelah 2 hari perawatan di NICU, bayi dinyatakan meninggal.

\section{DISKUSI}

Menggeser uterus ke sisi kiri tubuh pasien (LUD) selama RJP direkomendasikan bila uterus dapat dipalpasi atau terlihat ketinggian uterus diatas umbilikus (usia kehamilan 21-24 minggu) untuk mengurangi efek samping dari kompresi aortacaval oleh janin di uterus yang menyebabkan penurunan venous return dan cardiac output. Namun, kompresi vena cava dapat muncul pada kehamilan yang lebih awal. Ketentuan dilakukannya LUD harus berdasarkan kondisi setiap individu, seperti kehamilan multipel, polihidroamnion, atau kondisi lain dimana menyebabkan obstruksi vena cava walaupun usia kehamilan kurang dari 20 minggu.

Cardiac output yang dihasilkan dari kompresi dada akan optimal jika pasien hamil diposisikan pada permukaan yang keras (contohnya papan) dalam posisi terlentang dengan LUD. Rekomendasi terbaru menyatakan bahwa dengan dilakukannya LUD dengan pasien posisi terlentang diatas permukaan yang keras dapat mengurangi potensi kompresi dari uterus selama kompresi dada yang baik dilakukan. Protokol untuk kejadian henti jantung pada pasien wanita hamil dapat diadopsi dari American Heart Association yang tersaji pada Skema 1. 


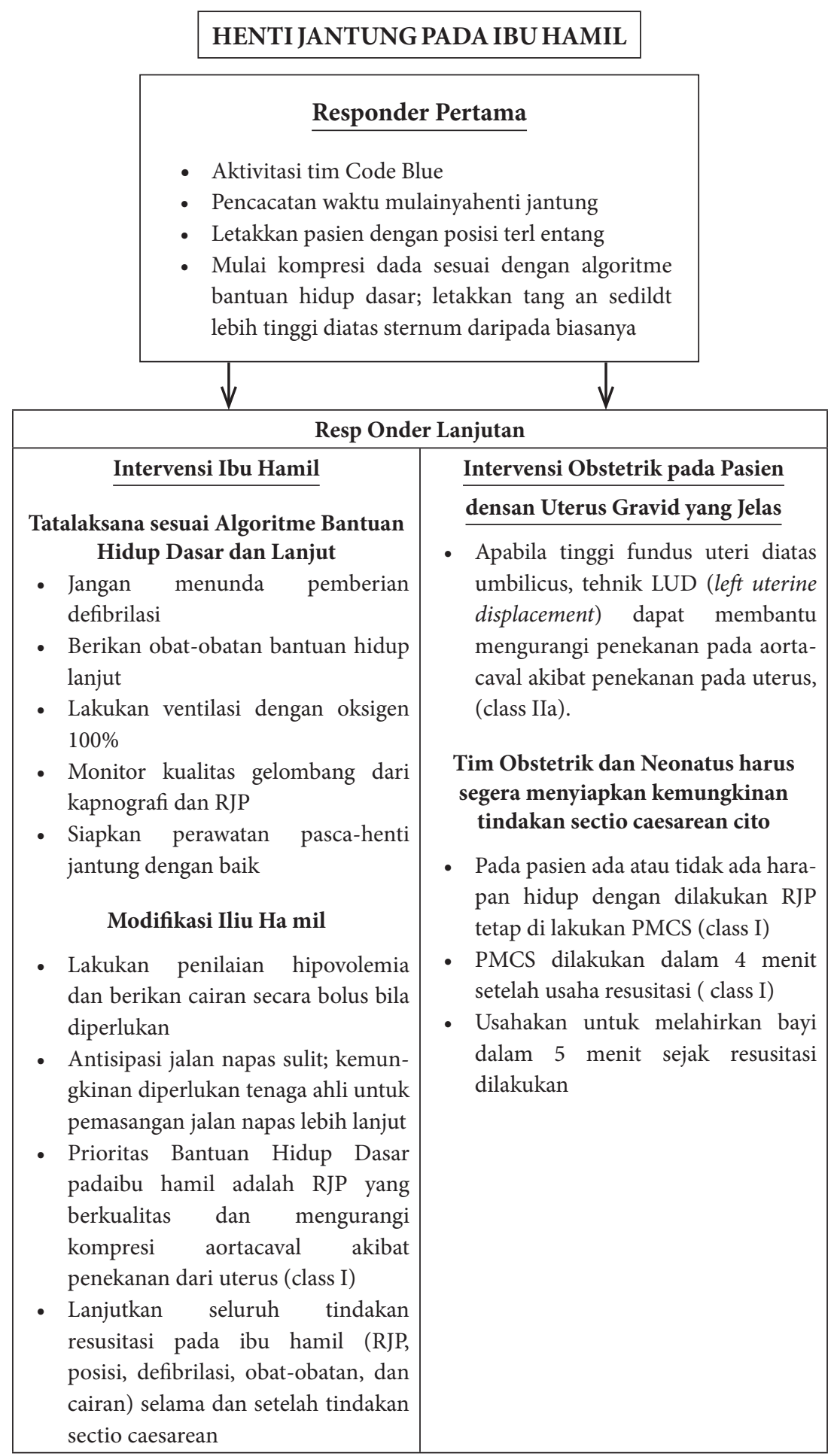

Skema 1 Algoritma penanganan henti jantung pada ibu hamil menurut AHA 2015

Tujuan utama dari PMSC adalah untuk mengosongkan uterus sehingga resusitasi pada ibu hamil dapat lebih baik dengan meningkatnya venous return dan cardiac output, memfasilitasi kompresi dada, mengurangi konsumsi oksigen, dan memudahkan dalam melakukan ventilasi. ${ }^{4} \mathrm{RJP}$ harus dilakukan terus menerus selama dan setelah PMSC. 5,6

Dalam laporan kasus serial Katz dan koleganya dari 38 tindakan PMSC dilaporkan 12 dari 20 pasien langsung kembali bersirkulasi spontan (return of spontaneous circulation atau ROSC) setelah melahirkan bayinya. Einav dan koleganya juga mendemonstrasikan keuntungan dari PMSC untuk kelangsungan hidup ibu sebesar 31,7\% dari 94 kasus PMSC yang diteliti dan tidak ada kasus yang menunjukkan perburukan pada status ibu setelah melahirkan bayinya. ${ }^{6}$

Ketika ibu dengan jelas tidak mungkin dapat bertahan hidup, sangat tepat bila segera dilakukan tindakan PMSC terutama bila janin dapat hidup. Untuk kasus henti jantung yang tidak disaksikan atau nadi yang tidak teraba berkepanjangan, dapat dilakukan PMSC secepatnya. ${ }^{9}$ Dalam kasus kami, RSUD tidak memiliki AED atau defibrilasi yang siap dan layak pakai dan pasien dilakukan pemindahan ke ruang operasi sehingga menambah waktu untuk prosedur PMSC dilakukan. Kematian dari bayi pada kasus ini diakibatkan oleh prematuritas.

\section{SIMPULAN}

Left uterine displacement (LUD) direkomendasikan selama RJP pada ibu hamil untuk mengurangi kompresi aortocaval dan meningkatkan venous return sehingga RJP akan lebih optimal. Gambar 1 menunjukkan teknik LUD yang dilakukan baik dengan satu tangan atau dua tangan. LUD dilakukan pada uterus yang teraba, dimana usia kehamilan lebih dari 20 minggu. Tujuan utama dari prosedur PMSC adalah untuk mengosongkan uterus sehingga memperbaiki resusitasi ibu. PMSC harus diputuskan dan dilakukan setelah 4 menit tidak ada respon dari RJP atau tidak ditemukannya detak jantung janin. Bayi harus dilahirkan 5 menit dari sejak henti jantung dengan tindakan RJP tetap dilakukan selama dan setelah PMSC.

\section{DAFTAR PUSTAKA}

1. Benson MD, Padovano A, Bourjeily G, Zhou Y. Maternal collapse: Challenging the four-minute rule. EbIoMedicine. 2016; $6: 253-257$.

2. Yildrim C, Goksu S, Kocoglu H, Gocmen A, Akdogan M, Gunay N. Perimortem cesarean delivery following severe maternal penetrating injury, Yonse Med J 2004; 45 (3): 561-3

3. Katz V, Balderston K, DeFreest M. Perimortem cesarean delivery: Were our assumptions correct? Am J ObstetGynecol 2005;103-120 
4. Parry R, Asmussen T, Smith J E. Perimortem caesarean section. Emerg Med J. 2016; 33: 224-229.

5. Katz VL. Perimortem caesarean delivery: Its role in maternal mortality. Semin Perinatol. 2012; 36 : 68-72.

6. Lee C Y, Kung SW. Perimortem caesarean section : A case report of an out-of-hospital arrest pregnant woman. World J Emerg Med 2018;9(1):70-72.

7. Chesnutt AN. Physiology of normal pregnancy. Crit Care Clin 2005;20: 609-615.

8. Drukker L, Hants Y, Sharon E, Sela HY, Grisaru-GranovskyS. Perimortem cesarean section for maternal and fetal salvage: concise review and protocol. Acta Obstet Gynecol Scand 2014; 93: 965-972.
9. Lavonas EJ, Drennan IR, Gabrielli A, Heffner AC, Hoyte CO, Orkin AM, et al. Part 10: Special Circumstances of Resuscitation: 2015 American Heart Association Guidelines Update for Cardiopulmonary Resuscitation and Emergency Cardiovascular Care. Circulation. 2015; 132 (18 Suppl2): 501-518.



This work is licensed under a Creative Commons Attribution 